\title{
EDITORIAL
}

\section{Developing core outcome set for women's, newborn, and child health: the CROWN Initiative}

\author{
Pediatric Research (2018) 84:316-317; https://doi.org/10.1038/ \\ s41390-018-0041-9
}

Clearly defined and relevant clinical outcomes of importance to all key stakeholders are essential if clinical trials, systematic reviews, and guidelines are to translate to the real world and improve patient care. Unfortunately, we have a long way to go in perinatal and pediatric health care. A recent systematic review of interventions for the prevention preterm birth included 103 randomized clinical trials in which 72 different outcomes were reported. This heterogeneity of outcomes limits the synthesis and usability of research, ${ }^{1}$ and contributes to research waste. ${ }^{2}$ Core outcome sets (COS) have been developed to address this problem. These are the agreed minimum set of outcomes to be reported in all clinical trials in a specific health condition or area and are also suitable for use in clinical audit or research other than randomized trials.

The Core Outcome Measures in Effectiveness Trials (COMET) Initiative (http://www.comet-initiative.org/) involves individuals interested in the development and application of agreed standardized sets of outcomes, known as "COSs". Core outcome sets are not meant to be restrictive, and clinical trials would ideally include core outcomes as well as other outcomes of interest. The COMET initiative describes a 5-step COS development process. ${ }^{3}$ These involve a review of existing knowledge and consensus development approaches to agreeing the COS. Similar to the publication of clear guidelines on clinical trial reporting such as CONSORT (http://www.equator-network.org/reporting-guidelines/ consort/) and PRISMA for systematic reviews (http://www.equatornetwork.org/reporting-guidelines/prisma/), standardized guidelines have been developed for COS. COS-STAD ${ }^{4}$ establishes minimum standards for the development of COS, and COS$\mathrm{STAR}^{5}$ provides guidance on the final reporting of COS. The importance of incorporating patient perspectives, including patient-reported outcome measures, ${ }^{6}$ in COS is increasingly recognized. $^{7}$

The CROWN collaboration (http://www.crown-initiative.org/) involves over 54 journals related to women's and newborn health who have come together to support The CoRe Outcomes in Women's and Newborn health (CROWN) Initiative (Aims of CROWN initiative: Box 1). This group has recently published the COS for studies aimed at preterm birth prevention ${ }^{8}$ and is committed to publishing and disseminating core outcomes to improve Women's and Newborn health.

Duffy et al. recently performed a systematic review of core outcomes in women's and newborn health; although this identified 49 COSs registered in women and newborn, only 3 of these related to newborn health. ${ }^{9}$ One of these is the COIN project: Core Outcomes In Neonatology (http:// neoepoch.com/core-outcomes/), which is establishing the most important outcomes for parents, children, and adults who received neonatal care, health-care professionals, and researchers. ${ }^{10}$
Over 20 years ago, perinatal health-care pioneered the application of systematic reviews to improve care. ${ }^{11}$ We propose that women's and newborn's health should again lead the way, reducing research waste and making research more relevant, by developing, disseminating, and applying core outcome sets. The journal Pediatric Research is delighted to demonstrate our interest in publishing core outcomes in newborn and child health, encouraging their use in clinical trials and furthering their wide dissemination, by becoming part of the CROWN Initiative.

List of CROWN member journals

1 Acta Obstetricia et Gynaecologica Scandinavica

2 American Journal of Obstetrics \& Gynaecology (AJOG)

3 American Journal of Perinatology

4 Archives of Gynaecology and Obstetrics

5 Australian and New Zealand Journal of Obstetrics and Gynaecology, The

6 Best Practice \& Research: Clinical Obstetrics \& Gynaecology

7 Birth: Issues in Perinatal Care

8 BJOG: An International Journal of Obstetrics and Gynaecology

9 BMC Pregnancy and Childbirth

10 BMC Women's Health

1 Breast Journal, The

2 Chinese Journal of Perinatal Medicine(中华围产医学杂志)

3 Climacteric

4 Clinical Obstetrics and Gynecology

5 Clinics in Perinatology

16 Cochrane Gynecology and Fertility Group

17 Cochrane Pregnancy and Childbirth Group

18 Contraception

19 Contraception \& Reproductive Medicine

20 Current Opinion in Obstetrics and Gynecology

21 European Journal of Contraception and Reproductive Health Care, The

22 European Journal of Obstetrics \& Gynecology and Reproductive Biology

23 Female Pelvic Medicine and Reconstructive Surgery

24 Fertility and Sterility

25 Fertility Research and Practice

26 Fetal Diagnosis and Therapy

27 Geburtshilfe und Frauenhelikunde

28 Ginekologia Polska

29 Gynecologic and Obstetric Investigation

30 Gynecologic Oncology

31 Gynecologic Oncology Reports

32 Gynecological Surgery

33 Human Fertility

34 Human Reproduction

35 Human Reproduction Update 
36 Hypertension in Pregnancy

37 International Breastfeeding Journal

38 International Journal of Childbirth

39 International Journal of Fertility and Sterility

40 International Journal of Gynecological Cancer

41 International Journal of Gynecology and Obstetrics

42 International Urogynecology Journal

43 Journal de Gynecologie Obstétrique et Biologie de la Reproduction

44 Journal of Family Planning and Reproductive Health Care

45 Journal of Gynecologic Oncology

46 Journal of Lower Genital Tract Disease

47 Journal of Maternal Fetal and Neonatal Medicine, The

48 Journal of Midwifery \& Women's Health

49 Journal of Minimally Invasive Gynecology

50 Journal of Obstetric, Gynecologic \& Neonatal Nursing

51 Journal of Obstetrics \& Gynecology

52 Journal of Obstetrics and Gynaecology Canada

53 Journal of Obstetrics and Gynecology Research

54 Journal of Ovarian Research

55 Journal of Pediatric \& Adolescent Gynecology

56 Journal of Perinatal \& Neonatal Nursing

57 Journal of Perinatal Medicine

58 Maternal and Child Nutrition

59 Maternal Health, Neonatology and Perinatology

60 MCN American Journal of Maternal Child Nursing, The

61 Menopause Review (Przegląd Menopauzalny)

62 Menopause: Journal of The North American Menopause Society, The

63 Midwifery

64 Nederlands Tijdschrift voor Obstetrie en Gynaecologie (NTOG)

65 Neurourology and Urodynamics

66 New Zealand College of Midwives Journal

67 Obstetrician \& Gynaecologist, The (TOG)

68 Obstetrics \& Gynecology

69 Paediatric and Perinatal Epidemiology

70 Pediatric Research

71 Placenta

72 Post Reproductive Health

73 Prenatal Diagnosis

74 Reproductive Health

75 Reproductive Health Library

76 Russian Journal of Obstetrics and Gynaecology
77 Twin Research and Human Genetics

78 Ultrasound in Obstetrics \& Gynecology

79 Women and Birth

80 Women's Midlife Health

Eleanor J. Molloy ${ }^{1}$, Chris Gale ${ }^{2}$, Michael Marsh ${ }^{3}$, Cynthia F. Bearer ${ }^{4}$, Declan Devane ${ }^{5}$ and Neena Modi ${ }^{6}$

${ }^{1}$ Discipline of Paediatrics, Trinity College, the University of Dublin, Dublin, Ireland; ${ }^{2}$ Department of Neonatal Medicine, Imperial College London, London, UK; ${ }^{3}$ British Journal of Obstetrics and Gynaecology, RCOG, 27 Sussex Place, London NW1 4RG, UK; ${ }^{4}$ Division of

Neonatology, Department of Pediatrics, University of Maryland School of Medicine, MD, USA; ${ }^{5}$ HRB-Trials Methodology Research Network, Department of Midwifery, NUI Galway, Galway, Ireland and ${ }^{6}$ Department of Neonatal Medicine, Imperial College London, London, UK Correspondence: Eleanor J. Molloy (Eleanor.molloy@tcd.ie)

\section{REFERENCES}

1. Meher S., Alfirevic Z. Choice of primary outcomes in randomised trials and systematic reviews evaluating interventions for preterm birth prevention: a systematic review. (2014). BJOG https://doi.org/10.1111/1471-0528.12593

2. Moher, D. et al. Increasing value and reducing waste in biomedical research: who's listening? Lancet. 387, 1573-1586 (2016).

3. Williamson, P.R. et al. The COMET Handbook: version 1.0.Trials. 18, 280 (2017).

4. Kirkham, J. J. et al. Core Outcome Set-STAndards for Development: the COS-STAD recommendations. PLoS Med. 14, e1002447 (2017). https://doi.org/10.1371/ journal.pmed.1002447.

5. Kirkham, J. J. et al. Core Outcome Set-STAndards for Reporting: the COS-STAR Statement. PLoS Med. 13, e1002148 (2016).

6. Macefield, R. C. et al. Developing core outcomes sets: methods for identifying and including patient-reported outcomes (PROs). Trials 15, 49 (2014). https://doi.org/ 10.1186/1745-6215-15-49.

7. Biggane, A. M., Brading, L., Ravaud, P., Young, B. \& Williamson, P. R. Survey indicated that core outcome set development is increasingly including patients, being conducted internationally and using Delphi surveys. Trials 19, 113 (2018). https://doi.org/10.1186/s13063-018-2493-y.

8. van 't Hooft, J. et al. CROWN initiative and preterm birth prevention: researchers and editors commit to implement core outcome sets. BJOG 125, 8-11 (2017).

9. Duffy, J. et al. International Collaboration to Harmonise Outcomes in Preeclampsia (iHOPE). Core outcome sets in women's and newborn health: a systematic review. BJOG 124, 1481-1489 (2017).

10. Webbe, J. et al. Developing, implementing and disseminating a core outcome set for neonatal medicine. Br. Med. J. Paediatr. Open 1, e000048 (2017).

11. Crowley P. Prophylactic corticosteroids for preterm birth. Cochrane Database Syst Rev. CD000065 (2000). 